OPEN ACCESS

Edited by:

Charles Christoph Roehr, University of Oxford, United Kingdom

Reviewed by:

Frans Walther,

UCLA Department of Pediatrics,

United States

Anup C. Katheria,

Sharp Mary Birch Hospital for

Women \& Newborns, United States

*Correspondence:

Laura Root

I.root@/umc.n

Specialty section:

This article was submitted to Neonatology,

a section of the journal

Frontiers in Pediatrics

Received: 03 May 2019 Accepted: 01 July 2019 Published: 16 July 2019

Citation:

Root L, van Zanten HA, den Boer MC

Foglia EE, Witlox RSGM and

te Pas AB (2019) Improving Guideline

Compliance and Documentation

Through Auditing Neonatal

Resuscitation. Front. Pediatr. 7:294

doi: 10.3389/fped.2019.00294

\section{Improving Guideline Compliance and Documentation Through Auditing Neonatal Resuscitation}

\author{
Laura Root ${ }^{1 *}$, Henriette A. van Zanten ${ }^{1}$, Maria C. den Boer ${ }^{1}$, Elizabeth E. Foglia ${ }^{2}$, \\ Ruben S. G. M. Witlox ${ }^{1}$ and Arjan B. te Pas ${ }^{1}$ \\ 1 Division of Neonatology, Department of Pediatrics, Leiden University Medical Center, Leiden, Netherlands, ${ }^{2}$ Division of \\ Neonatology, Department of Pediatrics, University of Pennsylvania School of Medicine, Philadelphia, PA, United States
}

Objective: Evaluate whether weekly audits of neonatal resuscitation using video and physiological parameter recordings improved guideline compliance and documentation in medical records.

Study design: Neonatal care providers of the Neonatal Intensive Care Unit (NICU) of Leiden University Medical Center reviewed recordings of neonatal resuscitation during weekly plenary audits since 2014. In an observational pre-post cohort study, we studied a cohort of infants born before and after implementation of weekly audits. Video and physiological parameter recordings of infants needing resuscitation were analyzed. These recordings were compared with the prevailing resuscitation guideline and corresponding documentation in the medical record using a pre-set checklist.

Results: A total of 212 infants were included, 42 before and 170 after implementation of weekly audits, with a median (IQR) gestational age of 30 (27-35) weeks vs. 30 (2933) weeks $(p=0.64)$ and birth weight of 1368 (998-1780) grams vs. 1420 (1097-1871) grams $(p=0.67)$. After weekly audits were implemented, providers complied more often to the guideline (63 vs. $77 \% ; p<0.001$ ). Applying the correct respiratory support based on heart rate and respiration, air conditions (dry vs. humidified air), fraction of inspired oxygen $\left(\mathrm{FiO}_{2}\right)$, timely start of interventions and evaluation of delivered care improved. Total number of correctly documented items in medical records increased from 39 to $65 \%(p<0.001)$. Greatest improvements were achieved in documentation of present providers, mode of respiratory support and details about transport to the NICU.

Conclusion: Regular auditing using video and physiological parameter recordings of infants needing resuscitation at birth improved providers' compliance with resuscitation guideline and documentation in medical records.

Keywords: neonate, newborn, neonatology, delivery room management, recordings

\section{INTRODUCTION}

The transition of a newly born is a complex event depending on several cardiopulmonary changes at birth. Guidelines containing step-by-step flowcharts on how to perform neonatal resuscitation are available for neonatal care providers to adequately provide care and improve outcome (1). To improve the quality of neonatal resuscitation, several Neonatal Intensive Care Units (NICUs) 
started recording and reviewing interventions in the delivery room (DR) on a regular basis (2-9). Reviewing vital physiological parameters and video imaging of neonatal resuscitation is reported to be a valuable audit tool for evaluating provided care (8) and can remove subjectivity (9-11).

We recently analyzed video and physiological parameter recordings of neonatal resuscitations performed at our unit. This study showed that providers often deviate from prevailing guidelines. Deviations mainly occurred within the first $30 \mathrm{~s}$ after birth. We speculated that these deviations were likely due to the stressful and often unpredictable circumstances during resuscitations (12). We also reported that documentation of DR management in the medical record was often incomplete and inaccurate, as compared to recordings (13). Our findings were in accordance with other studies observing guideline deviations (2, 14-16) or incomplete and inaccurate documentation of neonatal resuscitation (17-21). In order to improve DR management in our unit, we implemented weekly audits in 2014. The aim of this study was to assess whether weekly audits increased providers' compliance with the resuscitation guideline and improved documentation of DR management.

\section{MATERIALS AND METHODS}

A retrospective observational pre-post cohort study was performed at the NICU of Leiden University Medical Center (LUMC) in Leiden, the Netherlands, which is a tertiary level perinatal care center with an average of 850 intensive care admissions per year. During weekly audits, conducted since January 2014, we reviewed resuscitation recordings in plenary sessions. All NICU staff members were invited, but mostly neonatologists, fellows and residents attended audits. The audits took place in the morning, directly after handover, lasted about $15 \mathrm{~min}$ and were chaired by a coordinator who was also part of the NICU staff. During these audits, video recordings combined with respiratory function monitor recordings were used to evaluate delivered care in the DR. All providers were invited to provide feedback. Standard used evaluation criteria were hand hygiene, compliance to the prevailing resuscitation guideline, accuracy of documentation in the medical record, effect of interventions and lessons learned from the specific audit. During review of the recordings, providers received not only feedback on technical skills such as mask technique, but were also trained on cognitive skills such as physiology and clinical indications and behavioral skills such as communication.

We analyzed recordings of two cohorts of infants receiving support during transition after birth: before (2012-2013) and after (2016) the implementation of weekly audits. Recordings were compared with the prevailing local guideline for neonatal resuscitation and its documentation. Primary outcomes were total percentage of correctly performed and documented steps.

Plenary review of clinical performance can adversely affect providers. It is therefore important to design a review process that

\footnotetext{
Abbreviations: DR, delivery room; NICU, Neonatal Intensive Care Unit; $\mathrm{FiO}_{2}$, fraction of inspired oxygen; PEEP, positive end-expiratory pressure; PPV, positive pressure ventilation; HR, heart rate; AS, Apgar score.
}

is acceptable to all participating providers. We excluded the years 2014 and 2015, because during this period the review process was adapted to the providers' needs and a culture of auditing as standard care was established.

For the purpose of this study, recordings were only used if they were complete and of good quality (e.g., no missing measurements, intact video file, infant visible on video recording). Recordings were analyzed by one independent investigator (LR) who was not part of the medical team when the audits were conducted. Before implementation of weekly audits there were two trolleys (one in the DR and one in the operation room) containing the equipment needed for recording and recordings were only performed if time for set up was sufficient. In the period after implementation, physiological parameters and videos were recorded using an all-in-one device available on all six resuscitation tables. The New Life Box (NLB Neo-RDS, Applied Biosignals, Weener, Germany) was used to record respiratory parameters (positive end-expiratory pressure (PEEP), peak inspiratory pressure (PIP), expired tidal volume and mask leak). Oxygenation and heart rate (HR) were measured using the Masimo SET pulse oximeter (Masimo Radical, Masimo Corporation, Irvine, California, USA), which was placed around the infant's right hand. Fraction of inspired oxygen $\left(\mathrm{FiO}_{2}\right)$ was measured using a portable oxygen analyzer AX300-I (Teledyne Analytical Instruments, CA, USA), and applied pressure levels were registered by a variable orfice pneumometer (Avea Varflex Flow Transducer, Carefusion, Yorba Linda, CA, USA). All measurements were digitized and recorded at $200 \mathrm{~Hz}$ using the Bicore II (Cardinal Healthcare, Yorba Linda, CA) physiological recording system with Spectra physiological software (Grove Medical, London, UK) and Polybench software (Advanced Life Diagnostics, Weener, Germany).

The checklist for analysis of guideline compliance (Appendix a in Supplementary Material) was based on the same preset checklist used in our previous study (12). It contained observations and interventions needed to be performed according to our resuscitation guidelines, which are based on international and national guidelines. As in our previous study, we divided the guideline in step A, B and C. Step A contained all items "to be performed within $30 \mathrm{~s}$ after birth," such as heat loss prevention (blanket or wrap), appropriate type of air condition (dry or humidified air) and correct start of $\mathrm{FiO}_{2}$ (21\% or $\left.30 \%\right)$. Step B contained items "to be performed within $1 \mathrm{~min}$ after birth," such as the type of respiratory support given based on gestational age, HR and respiration. Step C contained items of cardiac resuscitation, to be performed "when the HR remained $<60$ beats per minute." According to the guidelines, providers are supposed to evaluate HR, breathing and oxygen saturation directly after birth and assess the condition of the neonate every $30 \mathrm{~s}$ to evaluate the effect of an intervention and determine further interventions.

Documentation of DR management was done retrospectively by one of the providers performing the resuscitation and was stored in Patient Data Management System (PDMS) (Metavision; IMDsoft, Tel Aviv, Israel), a digital medical record. The documentation was compared with the recordings, using the same checklist as in our previous study (Appendix b 
in Supplementary Material) (13). Analyzed documentation included notes of resuscitation reports divided in initial evaluation, respiratory support, oxygen therapy, intubation, cardiac resuscitation, transport to NICU and subjectivity of documentation. Items were compared to the recordings and scored as either correctly or incorrectly documented, or correctly or incorrectly not documented. Some items could not be observed in the video recordings, such as umbilical cord $\mathrm{pH}$, time of birth or time of transport to NICU. These items were only scored as being documented or not documented in the medical record. Baseline characteristics, such as year of birth, gestational age, gender, birth weight, mode of delivery, multiple birth and Apgar score (AS), were as well derived from PDMS.

All statistical analyses were performed using SPSS (SPSS for Windows, version 23, IBM, Chicago, IL, USA). Results are presented using the median (interquartile range (IQR)) or percentages. Chi-square tests were performed on categorical data. Mann Whitney $U$-tests were used for comparison of numerical data. A $p$-value $<0.05$ was considered statistically significant.

\section{RESULTS}

A total of 382 recordings of neonatal resuscitation were available. Recordings of 170 infants were excluded due to low quality of the recordings. The remaining recordings of 212 infants were analyzed: 42 recordings from infants born before and 170 from infants born after implementation of weekly audits. Baseline characteristics did not differ between cohorts with a median $(I Q R)$ gestational age of 30 (27-35) weeks vs. 30 (29-33) weeks $(p=0.64)$ and birth weight of $1368(998-1780)$ grams vs. 1420 (1097-1871) grams $(p=0.67)$ (Table 1).

\section{Compliance With Guideline}

After implementation of weekly audits, guideline compliance improved: the overall number of correctly performed steps increased from 63 to $77 \%(p<0.001)$.

\section{Step A}

Timely initial evaluation and interventions according to the guideline in step A increased significantly (before vs. after

TABLE 1 | Baseline characteristics.

\begin{tabular}{|c|c|c|c|}
\hline & 2012-2013 (n=42) & $2016(n=170)$ & $p$-value \\
\hline Male & $25(60)$ & $97(57)$ & $0.77^{\mathrm{a}}$ \\
\hline Preterm (<32 weeks) & $26(62)$ & $120(70)$ & $0.28^{a}$ \\
\hline Gestational age (in weeks) & 30 (27-35) & $30(29-33)$ & $0.64^{b}$ \\
\hline Birth weight (in grams) & $1368(998-1780)$ & $1420(1097-1871)$ & $0.67^{b}$ \\
\hline Born by cesarean section & $22(52)$ & $104(61)$ & $0.30^{\mathrm{a}}$ \\
\hline Multiple birth & $11(26)$ & $62(36)$ & $0.21^{a}$ \\
\hline \multicolumn{4}{|l|}{ AS documented } \\
\hline $1 \min$ & $6(4-7)$ & $6(3-8)$ & $0.90^{b}$ \\
\hline $5 \mathrm{~min}$ & $8(6-9)$ & $8(7-9)$ & $0.41^{\mathrm{b}}$ \\
\hline $10 \min$ & $9(7-9)$ & $9(8-9)$ & $0.32^{b}$ \\
\hline
\end{tabular}

Data are presented as $n$ (\%) or median (IQR).

${ }^{a}$ Chi-Squared test.

${ }^{b}$ Mann-Whitney U-test.
TABLE 2 | Compliance with resuscitation guideline.

\begin{tabular}{|c|c|c|c|}
\hline & $\begin{array}{c}2012-2013 \\
(n=42)\end{array}$ & $\begin{array}{c}2016 \\
(n=170)\end{array}$ & $p$-value \\
\hline \multicolumn{4}{|c|}{ STEP A "WITHIN 30 S AFTER BIRTH" } \\
\hline $\begin{array}{l}\text { Time of arrival on } \\
\text { resuscitation table (s) }\end{array}$ & $37(25-60)$ & $33(19-52)$ & $0.30^{\mathrm{b}}$ \\
\hline$<30 s$ & 12 (32) & $63(45)$ & $0.13^{a}$ \\
\hline $\begin{array}{l}\text { Time from arrival to wearing } \\
\text { a hat (s) }\end{array}$ & $8(3-14)$ & $8(4-13)$ & $0.98^{\mathrm{b}}$ \\
\hline$<30 \mathrm{~s}$ & $7(20)$ & 38 (32) & $0.18^{\mathrm{a}}$ \\
\hline Correctly blanket or wrap & $42(100)$ & 168 (99) & $1.00^{\mathrm{C}}$ \\
\hline $\begin{array}{l}\text { Appropriate type of air } \\
\text { condition }\end{array}$ & $31(74)$ & $170(100)$ & $<0.001^{\mathrm{C}}$ \\
\hline Auscultation HR performed & $36(86)$ & $147(86)$ & $0.98^{\mathrm{a}}$ \\
\hline $\begin{array}{l}\text { Time from arrival to } \\
\text { auscultation (s) }\end{array}$ & $32(19-56)$ & $37(20-66)$ & $0.47^{\mathrm{b}}$ \\
\hline$<30 \mathrm{~s}$ & $2(6)$ & $23(16)$ & $0.17^{\mathrm{C}}$ \\
\hline Duration HR evaluation (s) & $12(5-20)$ & $13(8-22)$ & $0.19^{b}$ \\
\hline$>5 \mathrm{~s}$ & 27 (75) & $123(84)$ & $0.19^{a}$ \\
\hline Correct start of $\mathrm{FiO}_{2}$ & $14(58)$ & $135(97)$ & $<0.001^{\mathrm{C}}$ \\
\hline \multicolumn{4}{|c|}{ STEP B "WITHIN 1 MIN AFTER BIRTH" } \\
\hline $\begin{array}{l}\text { Time from arrival to start } \\
\text { support (s) }\end{array}$ & $34(19-74)$ & $16(10-26)$ & $<0.001^{b}$ \\
\hline$<1$ min after birth & $10(28)$ & 98 (70) & $<0.001^{a}$ \\
\hline $\begin{array}{l}\text { Correct start PEEP (cm } \\
\mathrm{H} 2 \mathrm{O})\end{array}$ & $35(95)$ & $134(89)$ & $0.53^{\mathrm{C}}$ \\
\hline $\begin{array}{l}\text { Correct first step (type of } \\
\text { respiratory support given) }\end{array}$ & $29(73)$ & 144 (89) & $0.006^{\mathrm{a}}$ \\
\hline $\begin{array}{l}\text { Correct pressure 1st } \\
\text { sustained inflation }(\mathrm{cm} \mathrm{H} 2 \mathrm{O})\end{array}$ & $24(82)$ & $100(88)$ & $0.37^{\mathrm{C}}$ \\
\hline $\begin{array}{l}\text { Correct duration 1st } \\
\text { sustained inflation (s) }\end{array}$ & $12(43)$ & $60(58)$ & $0.15^{\mathrm{a}}$ \\
\hline 2nd evaluation performed & $19(68)$ & 101 (99) & $<0.001^{\mathrm{a}}$ \\
\hline $\begin{array}{l}\text { Correct duration 2nd } \\
\text { evaluation (s) }\end{array}$ & $13(46)$ & $85(83)$ & $<0.001^{\mathrm{a}}$ \\
\hline $\begin{array}{l}\text { Correct 2nd step (type of } \\
\text { respiratory support given) }\end{array}$ & $20(71)$ & 101 (98) & $<0.001^{\mathrm{C}}$ \\
\hline $\begin{array}{l}\text { Correct pressure 2nd step } \\
(\mathrm{cm} \mathrm{H} 2 \mathrm{O})\end{array}$ & $18(78)$ & 54 (73) & $0.61^{a}$ \\
\hline $\begin{array}{l}\text { Correct duration 2nd } \\
\text { sustained inflation (s) }\end{array}$ & - & $29(43)$ & - \\
\hline 3rd evaluation performed & $20(87)$ & $67(93)$ & $0.39^{a}$ \\
\hline $\begin{array}{l}\text { Correct duration 3rd } \\
\text { evaluation (s) }\end{array}$ & $19(83)$ & $50(69)$ & $0.20^{\mathrm{a}}$ \\
\hline
\end{tabular}

Data are presented as $n$ (\%) or median (IQR).

a Chi-Squared test.

${ }^{b}$ Mann-Whitney U-test.

${ }^{c}$ Fisher's exact test.

implementation of weekly audits: 58 vs. $72 \%$; $p<0.001$ ). After implementation, all infants received appropriate air condition (dry or humidified air) during respiratory support (74 vs. $100 \%$; $p<0.001)$, and providers started with the correct $\mathrm{FiO}_{2}(58 \%$ vs. 97\%; $p<0.001$ ) (Table 2).

\section{Step B}

Most significant improvements were made in step B (before vs. after implementation of weekly audits: 68 vs. $83 \%$; $p<$ 0.001). Improved items included start of appropriate respiratory 
support (28 vs. $70 \%$; $p<0.001$ ), as well as applying the correct respiratory support based on $\mathrm{HR}$ and respiration (73 vs. $89 \%$; $p=0.006)$ (Table 2).

\section{Step C}

Two infants received chest compressions, both after implementation of weekly audits. Indication and technique were both correct, as the combination of ventilation vs. compressions was 1:3 and chest compressions were performed with 2 thumbs or 2 fingers.

\section{Accuracy of Documentation}

After implementation of weekly audits, accuracy of documentation of DR management improved significantly (before vs. after implementation of weekly audits: 39 vs. $65 \% ; p<0.001)$.

\section{Initial Evaluation}

Documentation improved in the following items: providers present at resuscitation ( 2 vs. $82 \%$; $p<0.001$ ), physical condition of infants upon arrival on the resuscitation table (69 vs. $95 \%$; $p<$ 0.001 ), quality of breathing at first impression (60 vs. $91 \%$; $p<$ $0.001)$, and documentation of umbilical cord blood gas samples (43 vs. $68 \% ; p=0.002$ ) (Table 3 ).

\section{Respiratory Support}

Significant improvements in documentation included starting time of respiratory support ( 14 vs. $30 \% ; p=0.04$ ), whether sustained inflations (SI) were given (79 vs. $94 \% ; p=0.02)$ and ventilation pressures (32 vs. $77 \%$; $p<0.001$ ) (Table 3 ).

\section{Oxygen Therapy}

$\mathrm{FiO}_{2}$ was recorded in 25/42 infants before implementation and in 146/170 infants after implementation of weekly audits. Documentation of used supplemental oxygen (68 vs. $98 \%$; $p<$ 0.001 ), indication for oxygen therapy ( 12 vs. $35 \% ; p=0.02$ ) and effect of supplemental oxygen (28 vs. $78 \% ; p<0.001$ ) increased (Table 3 ).

\section{Intubation}

Intubation occurred in 4/42 infants before and 14/170 infants after implementation of weekly audits, which was correctly reported in both cohorts. Documenting the indication for intubation improved ( 25 vs. $86 \% ; p=0.04$ ). However, not all details were always reported, including the tube size ( 75 vs. $86 \%$; $p=1.00$ ), fixation depth (50 vs. $50 \% ; p=1.00)$, and the number of intubation attempts ( 25 vs. $57 \% ; p=0.58$ ).

\section{Cardiac Resuscitation}

Two infants received cardiac resuscitation after implementation of weekly audits. Indication and starting time of cardiac resuscitation was missing for one infant; duration was not reported for both.

\section{Transport to NICU}

Documentation about transport to the NICU improved significantly (before vs. after implementation of weekly audits). Improved items included type of respiratory support (66 vs. $88 \%$;
TABLE 3 | Accuracy of documentation.

\begin{tabular}{|c|c|c|c|}
\hline & $\begin{array}{c}2012-2013 \\
(n=42)\end{array}$ & $\begin{array}{c}2016 \\
(n=170)\end{array}$ & $p$-value \\
\hline \multicolumn{4}{|l|}{ GENERAL } \\
\hline Time of birth & $40(95)$ & $167(98)$ & $0.26^{a}$ \\
\hline Umbilical cord pH & $18(43)$ & $116(68)$ & $0.002^{a}$ \\
\hline Providers present & $1(2)$ & $139(82)$ & $<0.001^{\mathrm{a}}$ \\
\hline \multicolumn{4}{|c|}{ INITIAL EVALUATION AT BIRTH } \\
\hline Clinical condition & $29(69)$ & $161(95)$ & $<0.001^{a}$ \\
\hline $\mathrm{HR}$ & $20(48)$ & $101(59)$ & $0.17^{\mathrm{a}}$ \\
\hline Oxygen saturation & $4(10)$ & $30(18)$ & $0.20^{a}$ \\
\hline Quality of breathing & $25(60)$ & $155(91)$ & $<0.001^{a}$ \\
\hline \multicolumn{4}{|l|}{ RESPIRATORY SUPPORT } \\
\hline $\begin{array}{l}\text { Type of 1st respiratory } \\
\text { support given }\end{array}$ & 35 (95) & $148(99)$ & $0.18^{b}$ \\
\hline $\begin{array}{l}\text { Starting time respiratory } \\
\text { support }\end{array}$ & $5(14)$ & $45(30)$ & $0.04^{a}$ \\
\hline Indication respiratory support & $15(41)$ & $69(46)$ & $0.55^{a}$ \\
\hline Sustained inflations (SI) given & $26(79)$ & $102(94)$ & $0.02^{b}$ \\
\hline $\begin{array}{l}\text { Consecutive inflations (PPV) } \\
\text { given }\end{array}$ & $18(60)$ & $74(80)$ & $0.02^{a}$ \\
\hline Ventilation pressures used & $12(32)$ & $116(77)$ & $<0.001^{\mathrm{a}}$ \\
\hline Ventilation pressures adjusted & $10(29)$ & $120(86)$ & $<0.001^{\mathrm{a}}$ \\
\hline Effect on HR & $11(30)$ & $83(55)$ & $0.005^{\mathrm{a}}$ \\
\hline Effect on oxygen saturation & $14(38)$ & $123(82)$ & $<0.001^{a}$ \\
\hline Duration of respiratory & $2(5)$ & $7(5)$ & $1.00^{b}$ \\
\hline
\end{tabular}

support

\begin{tabular}{lccc} 
OXYGEN THERAPY & $139(98)$ & $<0.001^{\mathrm{b}}$ \\
$\begin{array}{l}\text { Use of supplemental oxygen } \\
\text { Starting time of oxygen }\end{array}$ & $17(68)$ & $21(15)$ & $0.20^{\mathrm{a}}$ \\
therapy & $3(12)$ & $50(35)$ & $0.02^{\mathrm{a}}$ \\
$\begin{array}{l}\text { Indication for oxygen therapy } \\
\text { Starting point of oxygen }\end{array}$ & $3(12)$ & $73(51)$ & $<0.001^{\mathrm{a}}$ \\
therapy & & $117(82)$ & $<0.001^{\mathrm{b}}$ \\
$\begin{array}{l}\text { Maximum level of FiO } 2 \\
\text { Effect of supplemental oxygen }\end{array}$ & $7(28)$ & $110(78)$ & $<0.001^{\mathrm{a}}$ \\
$\begin{array}{l}\text { Duration of oxygen therapy } \\
\text { FiO } 2 \text { titrated during }\end{array}$ & $1(4)$ & $5(4)$ & $1.00^{\mathrm{b}}$ \\
$\begin{array}{l}\text { resuscitation } \\
\text { TRANSPORT TO NICU }\end{array}$ & $10(40)$ & $122(86)$ & $<0.001^{\mathrm{a}}$ \\
$\begin{array}{l}\text { Time of transport to NICU } \\
\text { Type of support during }\end{array}$ & $1(2)$ & $19(11)$ & $0.14^{\mathrm{a}}$ \\
transport & $21(66)$ & $130(88)$ & $0.002^{\mathrm{a}}$ \\
$\begin{array}{l}\text { Ventilation pressures during } \\
\text { transport }\end{array}$ & $10(31)$ & $116(78)$ & $<0.001^{\mathrm{a}}$ \\
FiO 2 during transport & $13(41)$ & $121(82)$ & $<0.001^{\mathrm{a}}$ \\
\hline
\end{tabular}

Data are presented as $n$ (\%).

a Chi-Squared test.

b Fisher's exact test.

$p=0.002$ ), ventilator settings ( 31 vs. $78 \% ; p<0.001$ ), and $\mathrm{FiO}_{2}$ (41 vs. $82 \%$; $p<0.001$ ) (Table 3 ).

\section{Subjectivity of Documentation}

Subjective medical terms such as "low heart rate" and "pink" were frequently found in documentation (before vs. after 
implementation of weekly audits: 62 vs. $57 \%$; $p=0.57$ ). No non-medical terms (e.g., "looking bad") were used.

Documented AS were compared with the condition of the infant as observed in the recordings. When AS could be scored, similarity in AS was found in 45 vs. $64 \%(p=0.04)$ for AS $1 \mathrm{~min}$, 61 vs. $74 \%(p=0.004)$ for AS $5 \mathrm{~min}$, and 88 vs. $80 \%(p=0.14)$ for AS $10 \mathrm{~min}$.

\section{DISCUSSION}

This study showed that weekly audits, using video and physiological parameter recordings of infants receiving support during neonatal transition, improved guideline compliance and documentation in medical records.

Worldwide, several NICUs reported systematic recording of neonatal resuscitation for quality improvement (2-9). Benefits of recording real-time healthcare delivery for quality improvement purposes were reported (22), but previous studies failed to prove a significant improvement of overall clinical performance after reviewing recordings of neonatal resuscitation $(7,14$, 23, 24). A recent study showed that practice PPV (positive pressure ventilation) psychomotor training combined with team debriefings using video recordings of actual resuscitations may improve time to effective spontaneous breathing and adherence to guidelines during real neonatal resuscitations (25), but this study did not analyze complete neonatal resuscitation. To the best of our knowledge, our study is the first to prove significant improvement in overall guideline compliance and documentation of neonatal resuscitation after weekly plenary auditing. The International Liaison Committee on Resuscitation (ILCOR) (1) highlights the importance of good quality of neonatal resuscitation in their guideline. We therefore postulate that improved guideline compliance results in improved neonatal resuscitation. A recent study showed that guideline compliance improved clinical outcome after adult resuscitation (26). This may also apply to neonatal resuscitation, suggesting that weekly audits furthermore contributes to better patient outcomes.

Improvement in guideline compliance and documentation may be due to various factors. Studies reported that knowledge and skills quickly diminish after neonatal resuscitation training $(27,28)$, hence boosting personal level of knowledge and skills is highly recommended (29). Our weekly audits allow providers to continuously train, refresh knowledge, and learn from others. Although the resuscitation guideline changed during the study period, we still observed overall better guideline compliance, suggesting that regular auditing contributes to internalizing the prevailing guideline.

Reviewing recordings of neonatal resuscitation enables valuable discussions on subjectivity in the guideline and appropriateness of interventions during neonatal resuscitation for individual patients. Clinical parameters such as HR, chest excursions and color can be difficult to interpret as they are very subjective and subtle $(30,31)$. The use of electrocardiogram, pulse oximetry, and a respiratory function monitor can add objectivity to clinical assessment (9). Respiratory function monitor data, including ventilation pressures, mask leak, airway obstruction, and breathing pattern, can be discussed during audits, which results in objective feedback about the appropriateness of interventions (9).

Although documentation is the golden standard, documentation is almost never fully accurate. Accurate documentation enables reliable evaluation of resuscitation practice and legal review of medical records and ensures quality of post resuscitation care (13). Parameter recordings can add accuracy, as these can provide detailed information about the resuscitation process (9-11). Parameter recordings may therefore be a useful tool for completing documentation.

Auditing neonatal resuscitation allows providers to mutually provide feedback. Earlier we reported that providers would recommend other NICUs to implement audits, assuming that preconditions for a safe learning environment are met (32). Providers emphasized that audits should be blame and shame free, non-punitive, and focused on educational benefits, amongst others. Meeting preconditions for a safe learning environment allows providers to freely elaborate on their performances, which improves discussions during the audits.

Some NICUs that already implemented recording and reviewing neonatal resuscitation reported concerns about the legal and ethical implications of recording and auditing neonatal resuscitation and possible negative impact on providers (8, 33 , 34). These factors should be considered carefully upon implementation. When preconditions for a safe environment are met, we recommend other NICUs to record and review neonatal resuscitation on a regular basis.

This study is the first to investigate the influence of weekly audits on providers' guideline compliance and accuracy of documentation. However, it cannot simply be assumed that the overall improvement in guideline compliance (63 vs. $77 \%$ ) and accuracy of documentation ( 39 vs. $65 \%$ ) is fully effectuated by the audits and that this improvement is of clinical relevance, although our recent study showed that providers do experience recording and reviewing neonatal resuscitation as highly valuable for maintaining and improving resuscitation skills (32). Improvement in guideline compliance and documentation may also be caused by the awareness of being observed. This has been reported to improve the outcome in various studies $(22,35)$, and may apply specifically to rounding residents.

Our study does have some limitations. Due to convenience sampling in this retrospective pre-post cohort study we could not perform a power analysis. No observer bias occurred during analysis of the recordings, as only one researcher scored all data, but there is potential bias as the video reviewer was not blinded to the study phase. It is standard practice that video recording is simultaneously used with physiological parameters in our unit, however some recordings could not be used in our study due to an error in the video or measurement files, the infant being not visible on video due to camera angle, or missing documentation, amongst others. Pre- and post-implementation numbers of cases are not balanced as in the period before implementation of weekly audits there were only two trolleys containing the equipment needed for recording, and recordings were only performed if time for 
set up was sufficient. In the period after implementation, physiological parameters and video were recorded using an allin-one device available on six resuscitation tables, but technical problems with recordings sometimes persisted. Furthermore, we adapted our review process to providers' needs and we met preconditions for a safe environment. Therefore, we presume that it is unlikely that selection bias occurred during this study.

To score guideline compliance and accuracy of documentation we used the same pre-set checklists as in our previous studies $(12,13)$, which have not been externally validated. In order to increase validity in scoring guideline compliance it would be good to design an evidence based model to assess quality of neonatal resuscitation. Furthermore, including a guideline for documentation may improve accuracy, knowledge and in-depth understanding of neonatal resuscitation processes. As a result of weekly audits, documentation of neonatal resuscitation became more accurate. Discussions about documentation allowed providers to identify items crucial to report in medical records. For instance, documenting time until cord clamping could have given providers valuable insights in the efficiency of logistics directly after birth. More research is needed in order to decide on what items should be included in standard documentation.

Our weekly audits may still be optimized. For instance, adding audio to the recordings and inviting nurses during audits may improve the quality of delivered care even further. Furthermore, although we showed the effect of auditing on a weekly basis, it is unclear whether this effect would have been the same for auditing with another frequency. Further research is needed in order to determine the optimal frequency of audits, as frequently recurring short-lasting booster sessions, adjusted to the specific situation of a NICU, may allow for better integration in the daily routine of NICUs and extra exposure for providers (32).

\section{CONCLUSION}

Regular auditing using video and physiological parameter recordings of infants needing resuscitation at birth improved

\section{REFERENCES}

1. Wyllie J, Perlman JM, Kattwinkel J, Wyckoff MH, Aziz K, Guinsburg R, et al. Part 7: Neonatal resuscitation: 2015 International Consensus on Cardiopulmonary Resuscitation and Emergency Cardiovascular Care Science with Treatment Recommendations. Resuscitation. (2015) 95:e169201. doi: 10.1542/peds.2015-3373D

2. Gelbart B, Hiscock R, Barfield C. Assessment of neonatal resuscitation performance using video recording in a perinatal centre. J Paediatr Child Health. (2010) 46:378-83. doi: 10.1111/j.1440-1754.2010.01747.x

3. Konstantelos D, Gurth H, Bergert R, Ifflaender S, Rüdiger M. Positioning of term infants during delivery room routine handling - analysis of videos. BMC Pediatr. (2014) 14:33. doi: 10.1186/1471-2431-14-33

4. Konstantelos D, Ifflaender S, Dinger J, Rüdiger M. Suctioning habits in the delivery room and the influence on postnatal adaptation - a video analysis. $J$ Perinat Med. (2015) 43:777-82. doi: 10.1515/jpm-2014-0188 providers' compliance with resuscitation guideline and documentation in medical records. When preconditions for a safe environment are met, regular auditing can be recommended.

\section{DATA AVAILABILITY}

The datasets generated for this study are available on request to the corresponding author.

\section{ETHICS STATEMENT}

Recording video simultaneously with physiological parameters of neonatal resuscitation is considered standard care in the LUMC since 2016 and recordings thus became part of the medical record. In the Netherlands, no ethical approval is required for studies with anonymized data from medical records and for patient data collected during standard care. The LUMC Medical Ethics Committee provided a statement of no objection for conducting this study.

\section{AUTHOR CONTRIBUTIONS}

LR performed the literature search, data collection, interpretation and analysis, and wrote the manuscript. AtP conceptualized and designed the study, and reviewed, revised, and approved the manuscript. HvZ, MdB, EF, and RW critically reviewed the data analyses, and critically reviewed and approved the final manuscript for publication. All authors agree to be accountable for all aspects of the work.

\section{FUNDING}

AtP is recipient of a NWO innovational research incentives scheme (VIDI 91716428).

\section{SUPPLEMENTARY MATERIAL}

The Supplementary Material for this article can be found online at: https://www.frontiersin.org/articles/10.3389/fped. 2019.00294/full\#supplementary-material

5. Layouni I, Danan C, Durrmeyer X, Dassieu G, Azcona B, Decobert F. Video recording of newborn resuscitation in the delivery room: technique and advantages. Arch Pediatr. (2011) 18(Suppl. 2): S72-8. doi: 10.1016/S0929-693X(11)71094-6

6. Maya-Enero S, Botet-Mussons F, Fiqueras-Aloy J, Izquierdo-Renau M, Thió M, Iriondo-Sanz M. Adherence to the neonatal resuscitation algorithm for preterm infants in a tertiary hospital in Spain. BMC Pediatr. (2018) 18:319. doi: 10.1186/s12887-018-1288-3

7. Nadler I, Sanderson PM, Van Dyken CR, Davis PG, Liley HG. Presenting video recordings of newborn resuscitations in debriefings for teamwork training. BMJ Qual Saf. (2011) 20:163-9. doi: 10.1136/bmjqs.2010.043547

8. O'Donnell CP, Kamlin CO, Davis PG, Morley CJ. Ethical and legal aspects of video recording neonatal resuscitation. Arch Dis Child Fetal Neonatal Ed. (2008) 93:F82-4. doi: 10.1136/adc.2007.118505

9. van Vonderen JJ, van Zanten HA, Schilleman K, Hooper SB, Kitchen MJ, Witlox RS, et al. Cardiorespiratory monitoring during neonatal 
resuscitation for direct feedback and audit. Front Pediatr. (2016) 4:38. doi: $10.3389 /$ fped.2016.00038

10. Finer NN, Rich W. Neonatal resuscitation: toward improved performance. Resuscitation. (2002) 53:47-51. doi: 10.1016/S0300-9572(01)00494-4

11. Schmölzer GM, Kamlin OC, Dawson JA, te Pas AB, Morley CJ, Davis PG. Respiratory monitoring of neonatal resuscitation. Arch Dis Child Fetal Neonatal Ed. (2010) 95:F295-303. doi: 10.1136/adc.2009.165878

12. Schilleman K, Siew ML, Lopriore E, Morley CJ, Walther FJ, Te Pas AB. Auditing resuscitation of preterm infants at birth by recording video and physiological parameters. Resuscitation. (2012) 83:1135-9. doi: 10.1016/j.resuscitation.2012.01.036

13. Schilleman K, Witlox RS, van Vonderen JJ, Roegholt E, Walther FJ, te Pas $\mathrm{AB}$. Auditing documentation on delivery room management using video and physiological recordings. Arch Dis Child Fetal Neonatal Ed. (2014) 99:F48590. doi: 10.1136/archdischild-2014-306261

14. Carbine DN, Finer NN, Knodel E, Rich W. Video recording as a means of evaluating neonatal resuscitation performance. Pediatrics. (2000) 106:654-8. doi: 10.1542/peds.106.4.654

15. Lindbäck C, KC A, Wrammert J, Vitrakoti R, Ewald U, Målqvist M. Poor adherence to neonatal resuscitation guidelines exposed; an observational study using camera surveillance at a tertiary hospital in Nepal. BMC Pediatr. (2014) 14:233. doi: 10.1186/1471-2431-14-233

16. McCarthy LK, Morley CJ, Davis PG, Kamlin CO, O'Donnell CP, Timing of interventions in the delivery room: does reality compare with neonatal resuscitation guidelines? J Pediatr. (2013) 163:1553-7.e1. doi: 10.1016/j.jpeds.2013.06.007

17. Abe N, Catlin A, Mihara D. End of life in the NICU. A study of ventilator withdrawal. MCN Am J Matern Child Nurs. (2001) 26:141-6. doi: 10.1097/00005721-200105000-00010

18. Berglund S, Norman M. Neonatal resuscitation assessment: documentation and early paging must be improved! Arch Dis Child Fetal Neonatal Ed. (2012) 97:F204-8. doi: 10.1136/archdischild-2011-300295

19. Berglund S, Norman M, Grunewald C, Pettersson H, Cnattingius S. Neonatal resuscitation after severe asphyxia-a critical evaluation of 177 Swedish cases. Acta Paediatr. (2008) 97:714-9. doi: 10.1111/j.1651-2227.2008. 00803.x

20. Broussard M, Bass PF, Arnold CL, McLarty JW, Bocchini JA. Preprinted order sets as a safety intervention in pediatric sedation. J Pediatr. (2009) 154:865-8. doi: $10.1016 /$ j.jpeds.2008.12.022

21. Schoenfeld PS, Baker MD. Documentation in the pediatric emergency department: a review of resuscitation cases. Ann Emerg Med. (1991) 20:641-3. doi: 10.1016/S0196-0644(05)82383-2

22. Makary MA, Xu T, Pawlik TM. Can video recording revolutionise medical quality? BMJ. (2015) 351:h5169. doi: 10.1136/bmj.h5169

23. Ades A, Lee HC. Update on simulation for the Neonatal Resuscitation Program. Semin Perinatol. (2016) 40:447-54. doi: 10.1053/j.semperi.2016.08.005

24. Sawyer T, Sierocka-Castaneda A, Chan D, Berg B, Lustik M, Thompson M. The effectiveness of video-assisted debriefing versus oral debriefing alone at improving neonatal resuscitation performance: a randomized trial. Simul Health. (2012) 7:213-21. doi: 10.1097/SIH.0b013e3182578eae
25. Skåre C, Boldingh AM, Kramer-Johansen J, Calisch TE, Nakstad B, Nadkarni $\mathrm{V}$, et al. Video performance-debriefings and ventilation-refreshers improve quality of neonatal resuscitation. Resuscitation. (2018) 132:140-46. doi: $10.1016 /$ j.resuscitation.2018.07.013

26. Cheskes S, Schmicker RH, Rea T, Morrison LJ, Grunau B, Drennan IR, et al. The association between AHA CPR quality guideline compliance and clinical outcomes from out-of-hospital cardiac arrest. Resuscitation. (2017) 116:39-45. doi: 10.1016/j.resuscitation.2017.05.003

27. Matterson HH, Szyld D, Green BR, Howell HB, Pusic MV, Mally PV, et al. Neonatal resuscitation experience curves: simulation based mastery learning booster sessions and skill decay patterns among pediatric residents. $J$ Perinat Med. (2018) 46:934-41. doi: 10.1515/jpm-2017-0330

28. Patel J, Posencheg M, Ades A. Proficiency and retention of neonatal resuscitation skills by pediatric residents. Pediatrics. (2012) 130:515-21. doi: 10.1542/peds.2012-0149

29. Sawyer T, Umoren RA, Gray MM. Simulation and the Neonatal Resuscitation Program 7th Edition Curriculum. Vol. 17. 2016. e447-e453. doi: 10.1542/neo.17-8-e447

30. Brugada M, Schilleman $K$, Witlox RS, Walther FJ, Vento $M, T e$ Pas AB. Variability in the assessment of 'adequate' chest excursion during simulated neonatal resuscitation. Neonatology. (2011) 100:99-104. doi: $10.1159 / 000322009$

31. O'Donnell CP, Kamlin CO, Davis PG, Carlin JB, Morley CJ. Clinical assessment of infant colour at delivery. Arch Dis Child Fetal Neonatal Ed. (2007) 92:F465-7. doi: 10.1136/adc.2007.120634

32. den Boer MC, Houtlosser M, Foglia EE, Tan RNGB, Engberts DP, $\mathrm{Te}$ Pas $\mathrm{AB}$. Benefits of recording and reviewing neonatal resuscitation: the providers' perspective. Arch Dis Child Fetal Neonatal Ed. (2018). doi: 10.1136/archdischild-2018-315648. [Epub ahead of print].

33. den Boer MC, Houtlosser M, van Zanten HA, Foglia EE, Engberts $\mathrm{DP}$, Te Pas AB. Ethical dilemmas of recording and reviewing neonatal resuscitation. Arch Dis Child Fetal Neonatal Ed. (2018) 103:F280-f284. doi: 10.1136/archdischild-2017-314191

34. Gelbart B, Barfield C, Watkins A. Ethical and legal considerations in video recording neonatal resuscitations. J Med Ethics. (2009) 35:120-4. doi: $10.1136 /$ jme.2008.024612

35. Becker TE, Marique G. Observer effects without demand characteristics: an inductive investigation of video monitoring and performance. J Business Psychol. (2014) 29:541-553. doi: 10.1007/s10869-013-9338-1

Conflict of Interest Statement: The authors declare that the research was conducted in the absence of any commercial or financial relationships that could be construed as a potential conflict of interest.

Copyright (c) 2019 Root, van Zanten, den Boer, Foglia, Witlox and te Pas. This is an open-access article distributed under the terms of the Creative Commons Attribution License (CC BY). The use, distribution or reproduction in other forums is permitted, provided the original author(s) and the copyright owner(s) are credited and that the original publication in this journal is cited, in accordance with accepted academic practice. No use, distribution or reproduction is permitted which does not comply with these terms. 